\title{
True identity of endocapillary proliferation: a case of intravascular large $B$ cell lymphoma diagnosed with immunohistochemical study of kidney biopsy and literature review
}

\author{
Masao Iwagami - Rei Furuya - Daimu Tsutsumi - Yasuhiro Mochida • \\ Kunihiro Ishioka $\cdot$ Machiko Oka $\cdot$ Kyoko Maesato $\cdot$ Hidekazu Moriya \\ Takayasu Ohtake $\cdot$ Sumi Hidaka $\cdot$ Shuzo Kobayashi \\ Received: 20 December 2011/ Accepted: 10 April 2012/Published online: 26 May 2012 \\ (C) Japanese Society of Nephrology 2012
}

\begin{abstract}
A 78-year-old Japanese female presented with low-grade fever, malaise, and appetite loss lasting for 1 month. Upper and lower gastrointestinal endoscopy and contrast-enhanced whole-body computed tomography (CT) revealed no abnormal findings at a referring hospital. She was referred to our hospital because of bilateral leg edema and $2.5 \mathrm{~g} / \mathrm{day}$ proteinuria. Serum creatinine was $0.73 \mathrm{mg} / \mathrm{dl}$ and the kidneys were not enlarged. Kidney biopsy showed marked endocapillary proliferation with mesangiolysis. Soon after the kidney biopsy, her symptoms improved spontaneously, along with decreases in lactate dehydrogenase (LDH) from 503 to $197 \mathrm{IU} / \mathrm{l}, \mathrm{C}$-reactive protein (CRP) from 4.47 to $0.66 \mathrm{mg} / \mathrm{dl}$, and soluble interleukin-2 receptor (sIL-2R) from 1789 to $1001 \mathrm{U} / \mathrm{ml}$. Thus, she was followed carefully as an outpatient. One month later, however, she presented with dysarthria and right-sided hemiparesis, and diffusion-weighted brain magnetic resonance imaging (MRI) showed multiple high-intensity areas. She also had respiratory failure, and lung perfusion scintigraphy showed multiple low blood stream areas. Suspecting some endovascular abnormality, we performed immunohistochemical staining of the kidney biopsy specimen taken previously to find that endocapillary infiltrating cells were CD20-positive B lymphocytes. The infiltrating cells were confined to the endocapillary compartment in glomeruli and peritubular capillaries. Both clinical and pathological findings led us to diagnose intravascular large
\end{abstract}

M. Iwagami $(\bowtie) \cdot$ R. Furuya · D. Tsutsumi · Y. Mochida .

K. Ishioka $\cdot$ M. Oka $\cdot$ K. Maesato - H. Moriya - T. Ohtake ·

S. Hidaka $\cdot$ S. Kobayashi

Department of Nephrology, Immunology, and Vascular

Medicine, Shonan Kamakura General Hospital,

1370-1 Okamoto, Kamakura, Kanagawa 247-8533, Japan

e-mail: iwa1983@gmail.com
B cell lymphoma (IVLBCL). Two bone marrow biopsies and random skin biopsies were performed, but no abnormality was found. The present case demonstrates that clinical course and renal biopsy findings of intravascular large B cell lymphoma may mimic other renal conditions and that the identification of cell types with immunohistochemical staining may help establish an accurate diagnosis.

Keywords Intravascular large B cell lymphoma - Kidney biopsy · Immunohistochemical staining · Endocapillary proliferative glomerulonephritis · Lung perfusion scintigraphy $\cdot$ Brain magnetic resonance imaging

\section{Introduction}

Intravascular large B cell lymphoma (IVLBCL) is a rare subtype of lymphoma characterized by intracapillary proliferation of B lymphocytes in multiple organs, including the central nervous system (CNS), skin, bone marrow, liver, spleen, lungs, and kidneys [1-3]. Its clinical and imaging features include symptoms of infarction in various organs, in addition to fever of unknown origin and increased serum levels of lactate dehydrogenase (LDH), C-reactive protein (CRP), and soluble interleukin-2 receptor (sIL-2R). The disease is so rare that it is unlikely to be on a differential diagnosis list, making a definitive diagnosis difficult. If suspected, biopsies from infiltrated organs are associated with varying degrees of risk; high for the brain, spleen, and lungs, moderate for the liver and kidneys, and low for the skin and bone marrow. Only a small number of cases with IVLBCL proven with kidney biopsy have been reported since 1989 [4]. Here, we present a case report of a 78-year-old female with IVLBCL, the 
diagnosis of which was made based on the clinical course of the disease and immunohistochemical staining of a kidney biopsy specimen, to demonstrate a difficulty in diagnosing IVLBCL.

\section{Case report}

The patient is a 78-year-old Japanese female with a past medical history of hypertension for 30 years, myocardial infarction treated with a bare-metal stent in the anterior descending coronary artery 10 years ago, and arteriosclerosis obliterans treated with a stent graft in the right femoral artery 5 years ago. She presented with low-grade fever, malaise, and appetite loss in September 2010. Upper and lower gastrointestinal endoscopy, brain magnetic resonance imaging (MRI), and contrast-enhanced whole-body computed tomography (CT) performed at a referring hospital revealed no abnormal findings except a slightly enlarged spleen. Polymyalgia rheumatica was suspected because of a high level of CRP $(9.97 \mathrm{mg} / \mathrm{dl})$ and an elevated sedimentation rate $(106 \mathrm{~mm}$ at $1 \mathrm{~h})$. Oral prednisolone was, thus, started at a dose of $15 \mathrm{mg} /$ day in the middle of September. Oral dried thyroid agent was also prescribed for her decreased thyroid function diagnosed as primary hypothyroidism. Her symptoms temporarily improved, but worsened again after 1 month. She also developed bilateral leg edema, and urinalysis showed $(3+)$ and $2.5 \mathrm{~g} /$ day of proteinuria without any occult blood. She was, thus, referred to the nephrology department of our hospital in the middle of November 2010. As we were skeptical about the diagnosis of polymyalgia rheumatica, the patient was switched from oral prednisolone $15 \mathrm{mg}$ to hydrocortisone $15 \mathrm{mg}$, which is equivalent to prednisolone $3.75 \mathrm{mg}$, to prevent hypoadrenalism. She was admitted for further examination, including kidney biopsy, in the second week of December.

On admission, her vital signs revealed a low-grade fever of $37.2^{\circ} \mathrm{C}$, blood pressure of $134 / 77 \mathrm{mmHg}$, heart rate of $92 / \mathrm{min}$, respiratory rate of $20 / \mathrm{min}$, and percutaneous oxygen saturation of $94 \%$. Physical examination revealed paled palpebral conjunctiva and moderate pitting edema without any abnormal findings in the CNS, thyroid, heart, lungs, abdomen, lymph nodes, joints, or skin. Noteworthy laboratory data included high levels of LDH, CRP, and sIL2-R, and low levels of hemoglobin and albumin (Table 1). Serum creatinine was normal. Urinalysis revealed positive protein below the nephrotic range and negative occult blood. Four blood cultures were negative, and urine culture was positive for Klebsiella pneumoniae. Abdominal ultrasonography showed an enlarged spleen $(43 \times 127 \mathrm{~mm})$ and normal-sized kidneys (right $110 \times 45 \mathrm{~mm}$, left $104 \times 45 \mathrm{~mm}$ ). Contrast-enhanced whole-body CT taken in our hospital supported these findings, and showed no pulmonary embolism, enlarged lymph node, or liver abnormality. Echocardiography revealed no fistula, vegetation, or blood clot. Whole-body gallium scintigraphy did not show any abnormal uptake. MRI and magnetic resonance angiography (MRA) in our hospital also detected no brain lesion. A kidney biopsy was then performed.

Light microscopic (LM) examination of the kidney biopsy specimen containing six glomeruli revealed endocapillary proliferation and severe mesangiolysis without any membranous change (Fig. 1a, b). Generally, endocapillary proliferation was focal and segmental, while 2 of 6 glomeruli were globally infiltrated. The observed endocapillary cells did not appear to be segmented neutrophils, mesangial cells, or excess endothela, but were atypical nuclear cells. Mild infiltration of round cells and mild fibrotic change were observed in the tubulointerstitium (Fig. 1c). There was no specific change in the small arteries. Immunofluorescence staining was positive for fibrinogen on capillary walls, but negative for $\operatorname{IgG}, \operatorname{IgA}$, IgM, C3, and C1q. Electron microscopy (EM) revealed endocapillary occlusion by inflammatory cells consisting of lymphocytes, macrophages, and swollen endothelial cells. While electron-dense deposits were not detected, some cells were infiltrating into subendothelial spaces. Effacement and focal desquamation from the glomerular basement membranes of glomerular epithelial cells were noted (Fig. 1d).

After the kidney biopsy, her symptoms improved without any treatment except the low-dose oral hydrocortisone. Her body temperature decreased below $37^{\circ} \mathrm{C}$. She regained her appetite and energy level enough to walk around. Her serum LDH, CRP, and sIL-2R levels also decreased to $197 \mathrm{IU} / 1,0.66 \mathrm{mg} / \mathrm{dl}$, and $1001 \mathrm{U} / \mathrm{ml}$, respectively (Fig. 2). She was completely taken off $15 \mathrm{mg}$ hydrocortisone by the end of December and continued to show improvements in her symptoms and laboratory data thereafter, which suggested that the patient was on the way to recovery from some insult such as infection. Bone marrow biopsy for the differential diagnosis of inflammation of unknown origin revealed no abnormal findings such as the proliferation of atypical cells and hemophagocytic syndrome. She was discharged and carefully monitored in the outpatient clinic. She remained well for 1 month thereafter.

In the middle of February 2011, however, she was brought to the emergency room with dysarthria and rightsided hemiparesis. Diffusion-weighted MRI of the brain showed multiple high-intensity areas (Fig. 3a). On readmission, her vital signs revealed a high-grade fever of $38.7^{\circ} \mathrm{C}$, blood pressure of $152 / 90 \mathrm{mmHg}$, heart rate of $112 / \mathrm{min}$, respiratory rate of $28 / \mathrm{min}$, and percutaneous 


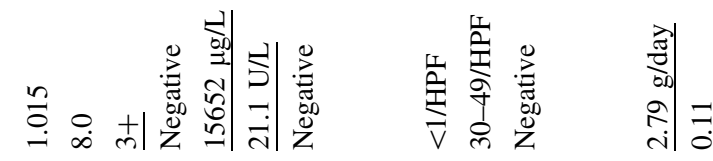

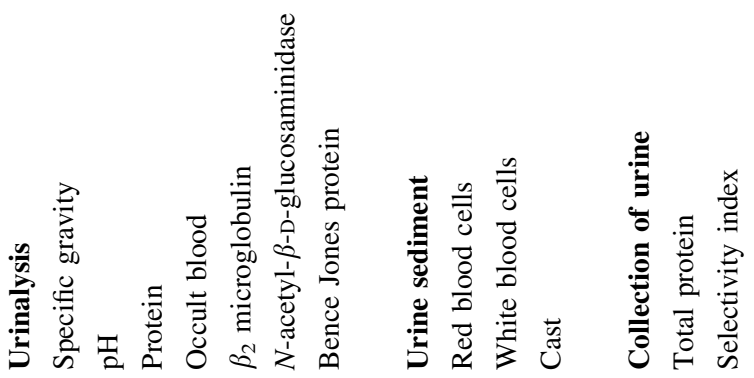

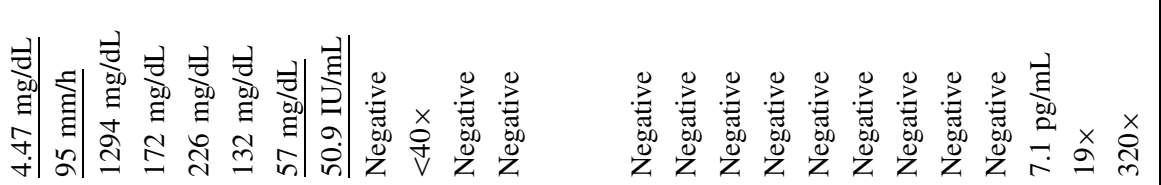

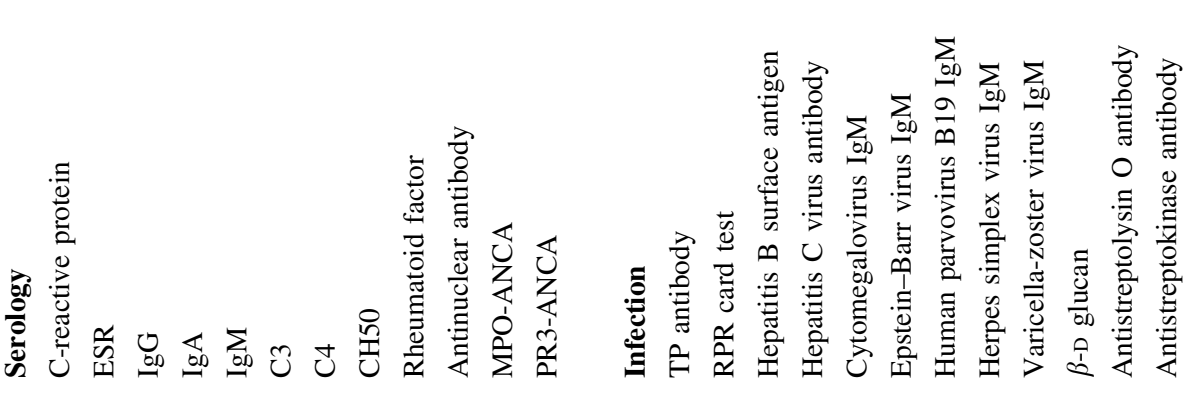

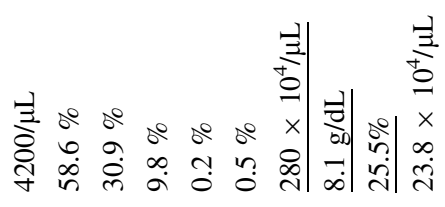

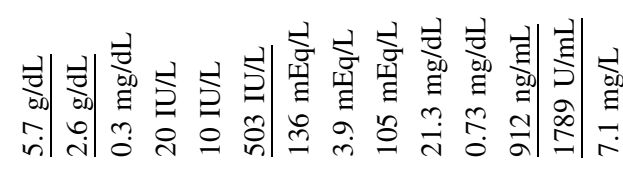

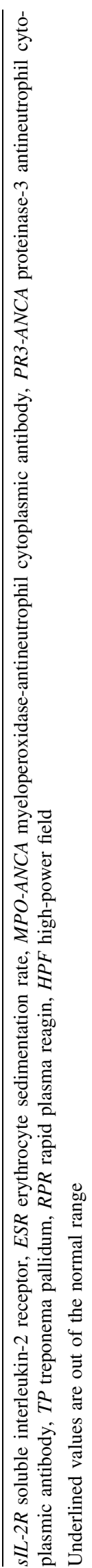



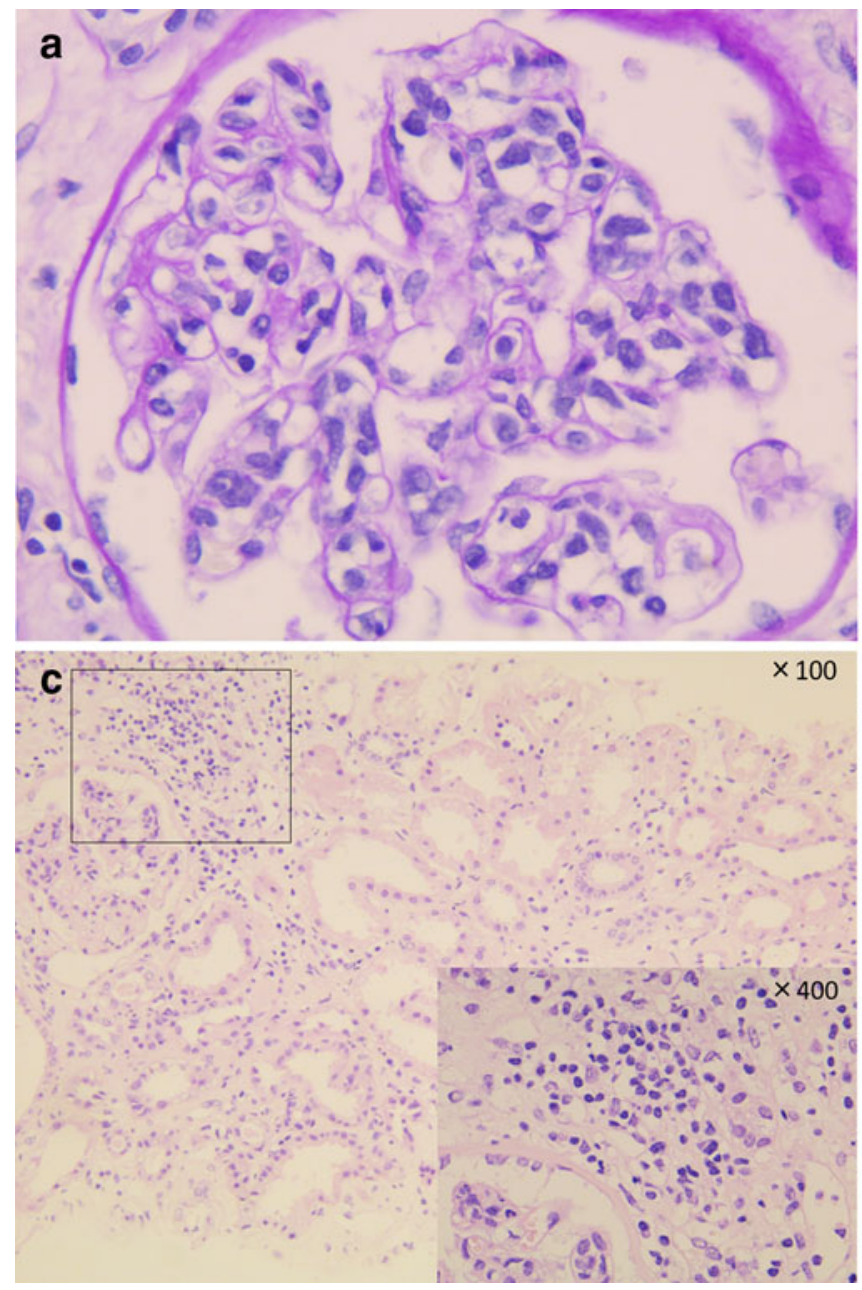

Fig. 1 Renal biopsy findings. a Periodic acid-Schiff staining $(\times 400)$ and b periodic acid methenamine silver staining $(\times 400)$ showing endocapillary proliferation with severe mesangiolysis without any membranous change. $\mathbf{c} H \& E$ stain $(\times 100$, insert $\times 400)$ showing mild infiltration of round cells in the tubulointerstitium. d Electron

oxygen saturation of less than $90 \%$. She also complained of difficulty in breathing. Lung perfusion scintigraphy revealed multiple low blood stream areas (Fig. 3b), while contrast-enhanced CT excluded pulmonary embolism. Her laboratory data also worsened, with increases in LDH to $463 \mathrm{IU} / \mathrm{L}, \mathrm{CRP}$ to $9.41 \mathrm{mg} / \mathrm{dL}$, sIL-2R to $1217 \mathrm{U} / \mathrm{mL}$ (Fig. 2), and proteinuria to a nephrotic level of $3.58 \mathrm{~g} /$ day, while her serum creatinine was still at the normal level of $0.77 \mathrm{mg} / \mathrm{dL}$

Suspecting some endovascular abnormality, we performed immunohistochemical staining of the kidney biopsy specimen taken 2 months ago to find that most intracapillary cells were CD20-positive B lymphocytes infiltrating (Fig. 4a, b). CD68-positive macrophages were also present and $\mathrm{CD} 3$-positive $\mathrm{T}$ lymphocytes were present but were fewer in number. The infiltrating B lymphocytes were confined to the endocapillary compartment in

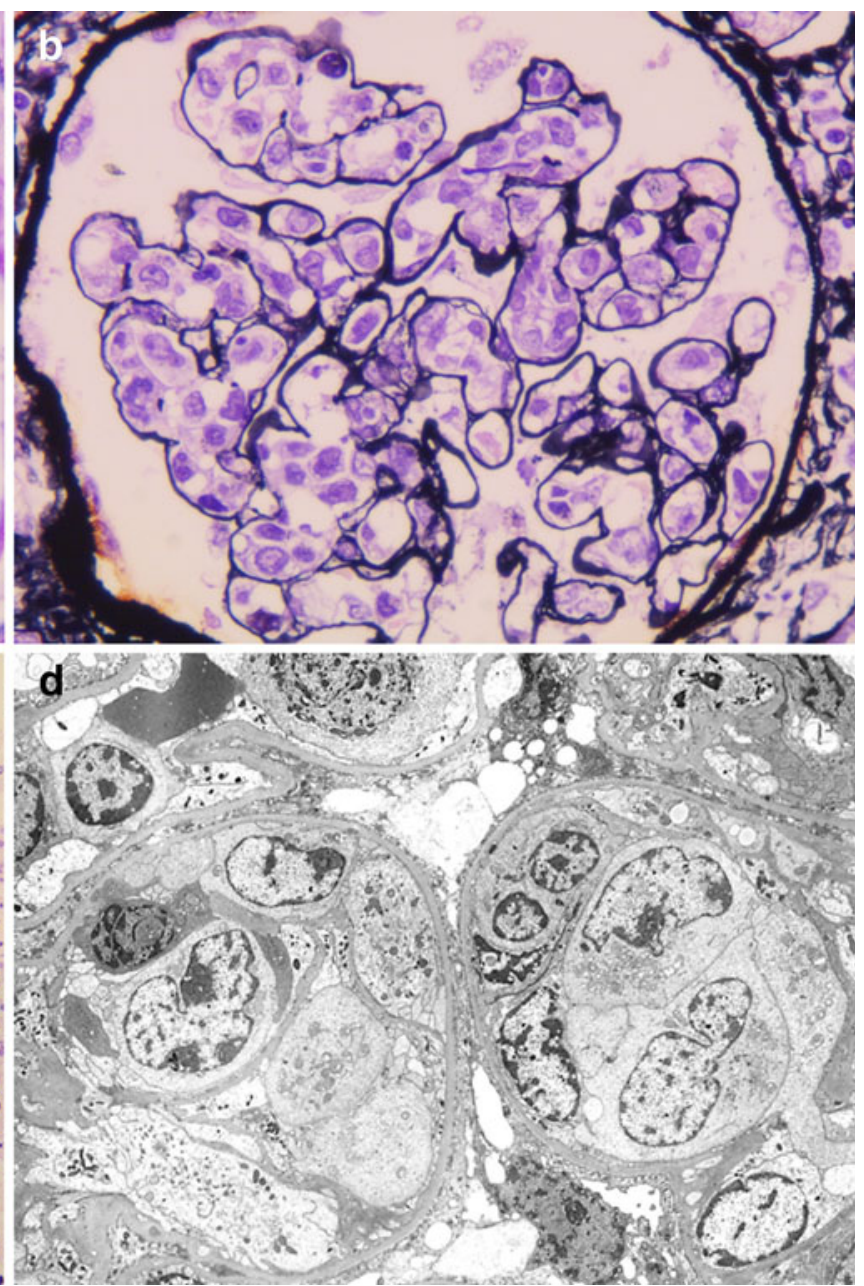

microscopy showing endocapillary proliferation of inflammatory cells such as lymphocytes, macrophages, and swollen endothelial cells, some of which are infiltrating into subendothelial spaces. Effacement and focal desquamation from the glomerular basement membranes of glomerular epithelial cells are noted

glomeruli and peritubular capillaries. Some glomeruli were highly infiltrated and others were mildly infiltrated. These pathological and clinical findings led us to make a definitive diagnosis of IVLBCL. A second bone marrow biopsy and random skin biopsies from the right arm, leg, and abdominal wall revealed no abnormality suggestive of hemophagocytic syndrome or lymphoma. Immunohistochemical CD-20 staining was also negative in the bone marrows and skin. R-CHOP (rituximab, cyclophosphamide, doxorubicin, vincristine, and prednisolone) therapy was initiated. However, immediately after the first dose of rituximab on day 1 , she fell into a coma. Brain MRI showed new lesions and the deterioration of existing lesions. Because of the unexpected reaction to rituximab, the treatment intent was changed to palliative care. After a short course of intravenous prednisolone sodium succinate ( $80 \mathrm{mg}$ for 2 days, $60 \mathrm{mg}$ for 5 days, and $30 \mathrm{mg}$ for 


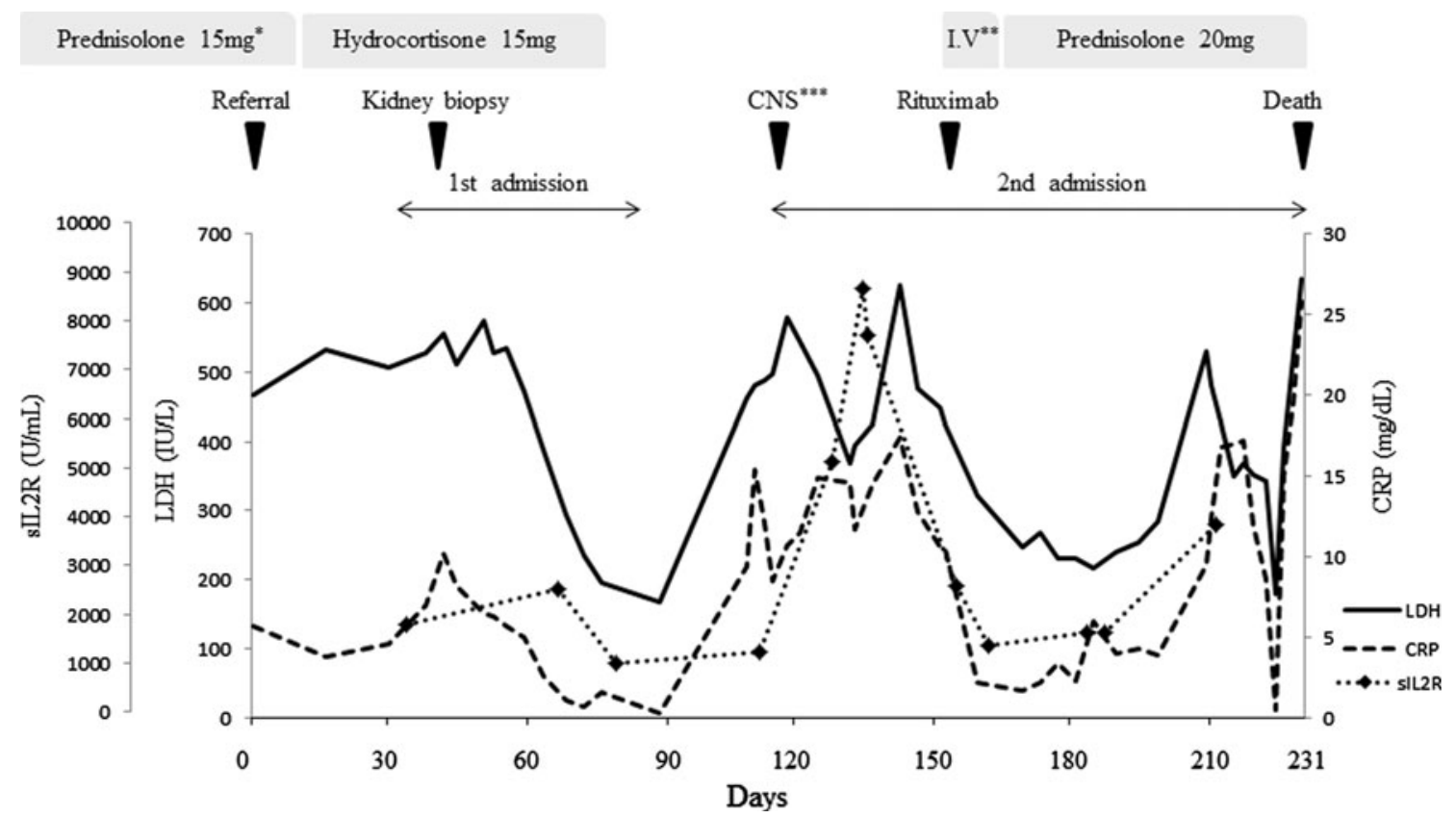

Fig. 2 Course of laboratory data after referral to our hospital. $L D H$ lactate dehydrogenase, $C R P$ C-reactive protein, $s I L-2 R$ soluble interleukin-2 receptor, *Prednisolone $15 \mathrm{mg}$ started 45 days before referral to our hospital. **A short course of intravenous prednisolone

3 days) and 3 months of oral prednisolone use (20 mg qd), she died of respiratory failure. Consent for autopsy could not be obtained.

\section{Discussion}

This is the case in which the definitive diagnosis of IVLBCL was difficult before the disease flare up and immunohistochemical analysis of endocapillary cells. Temporary improvement of clinical symptoms and laboratory values, and lack of bone marrow involvement precluded a timely diagnosis of IVLBCL. Neither CNS nor pulmonary symptoms were present at the time of kidney biopsy, raising the possibility that the disease started with a kidney-limited form and progressed to a more disseminated form. However, an autopsy study by Wick et al. [5] demonstrated intracapillary proliferation of lymphoma cells in organs without any clinical sign. This indicates that the disease may remain silent in multiple organs until it becomes clinically manifest by exceeding a threshold specific to each organ. We were unable to explore this aspect because autopsy consent could not be obtained. Another feature unique to this case was that her condition temporarily improved, which might be partly explained by the short course of low-dose oral steroid used. However, her symptoms and laboratory data continued to improve even after the steroid was tapered and discontinued, leaving sodium succinate ( $80 \mathrm{mg}$ for 2 days, $60 \mathrm{mg}$ for 5 days, and $30 \mathrm{mg}$ for 3 days). *** Manifestation of central nervous system involvement with dysarthria and right-sided hemiparesis

the impression that the disease would resolve spontaneously with careful observation alone, though there are reports describing a case of IVLBCL with a "waxing and waning" course [6, 7].

Pathologically, the differential diagnosis of endocapillary proliferation includes post-infectious glomerulonephritis, IgA nephropathy, membranoproliferative glomerulonephritis, cryoglobulinemic glomerulonephritis, diabetic nephritis, lupus nephritis class IV, and IVLBCL. It is of particular importance to differentiate IVLBCL from post-infectious glomerulonephritis by pathological examination, because the clinical courses of the two conditions may be similar, as seen in this case. Post-infectious glomerulonephritis and infectious glomerulonephritis with sepsis, which are essentially equivalent to endocapillary proliferative glomerulonephritis in terms of pathological features, are characterized by the proliferation of mainly mononuclear and polymorphonuclear neutrophils. IVLBCL may show atypical lymphocytes with heteromorphic nuclei, which are sometimes difficult to identify with LM. In addition to morphological features of nuclei, the distribution of endocapillary proliferation seems to be important and can be easily assessed with LM; the distribution is typically diffuse and global in post-infectious glomerulonephritis, while it may be focal and segmental in IVLBCL. EM provides additional information for differential diagnosis. EM in this case revealed not only details of proliferating cells in the absence of electron-dense deposits, but 

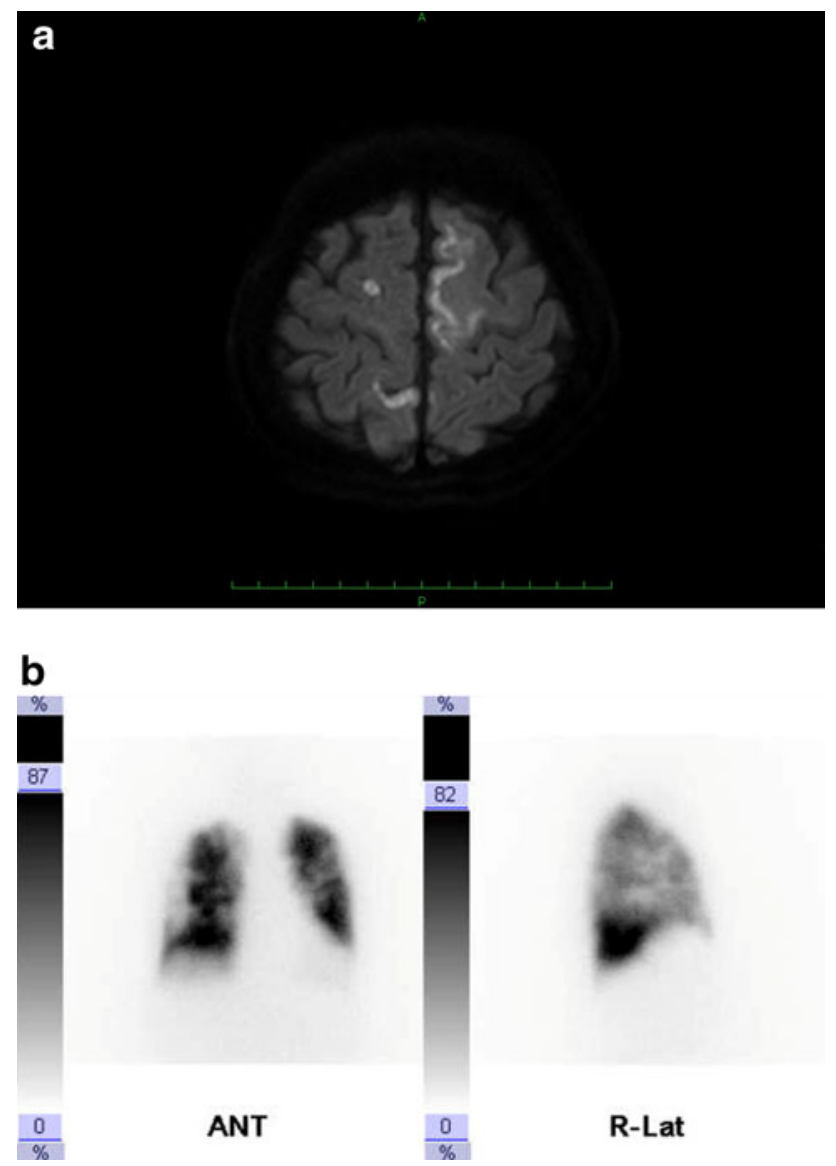

Fig. 3 a Magnetic resonance imaging (MRI) (diffusion-weighted image) showing multiple high-intensity areas on re-admission, and b pulmonary blood stream scintigraphy showing multiple low blood stream areas

also widely injured glomerular epithelial cells, which may explain her proteinuria. Possible reasons for her normal serum creatinine level despite severe mesangiolysis and injured glomerular epithelial cells are that lesions were focal and segmental, and that the tubulointerstitium was well preserved. Although immunohistochemical analysis of endocapillary cells is not part of our routine diagnostic process for endocapillary proliferation, the identification of cell types with immunohistochemical staining may play a critical role in the establishment of an accurate diagnosis, as in this case. Furthermore, Kusaba et al. [8] revealed a lack of CD11a expression on lymphoma cells in their immunohistochemical analysis of a renal biopsy specimen taken from a case of IVLBCL and concluded that the adhesion molecule could be a candidate factor preventing the transvascular migration of lymphoma cells. Immunohistochemistry may, thus, play an important role in not only the diagnosis of the disease but also the development of treatment strategies in the future.

There have been several case reports with literature reviews of IVLBCL diagnosed with kidney biopsy. In
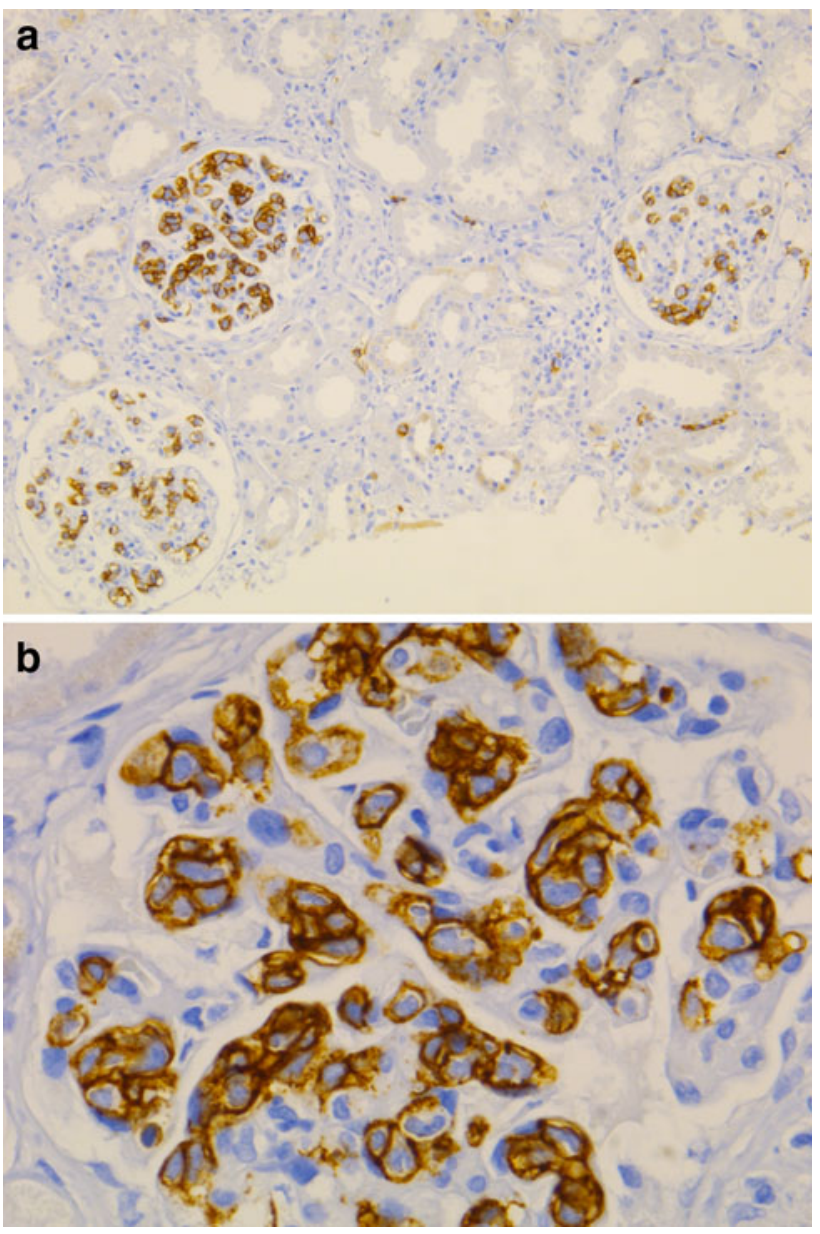

Fig. 4 Renal biopsy findings. Immunoperoxidase staining with antiCD20 $(\mathbf{a} \times 100$ and $\mathbf{b} \times 400)$

2003, Törnroth et al. [9] reviewed 55 reported cases of lymphoma diagnosed by percutaneous kidney biopsy, of which 11 were of intraglomerular type considered as a renal manifestation of IVLBCL and the rest were of interstitial type. Several additional cases have been reported since then. Table 2 is the first attempt to summarize relevant renal and extra-renal findings of the previously reported IVLBCL cases proven with kidney biopsy [4, 8-23], except for one case of IVLBCL complicated with renal cell carcinoma reported in 2001 [24] and two cases of IVLBCL showing intracapillary proliferation only within peritubular capillaries reported in 2007 and 2011 [25, 26]. The table shows wide individual variations in renal laboratory findings and LM findings of kidney specimens. Only a few cases had severe forms of endocapillary B cell proliferation [8, 13, 15]. Kidney biopsies of eight cases were entirely negative by immunofluorescence (IF). Two cases, including the present case, were positive only for fibrinogen. This supports the importance of IF findings in differentiating IVLBCL from other disease entities. Another feature common to most IVLBCL cases proven with kidney biopsy is 


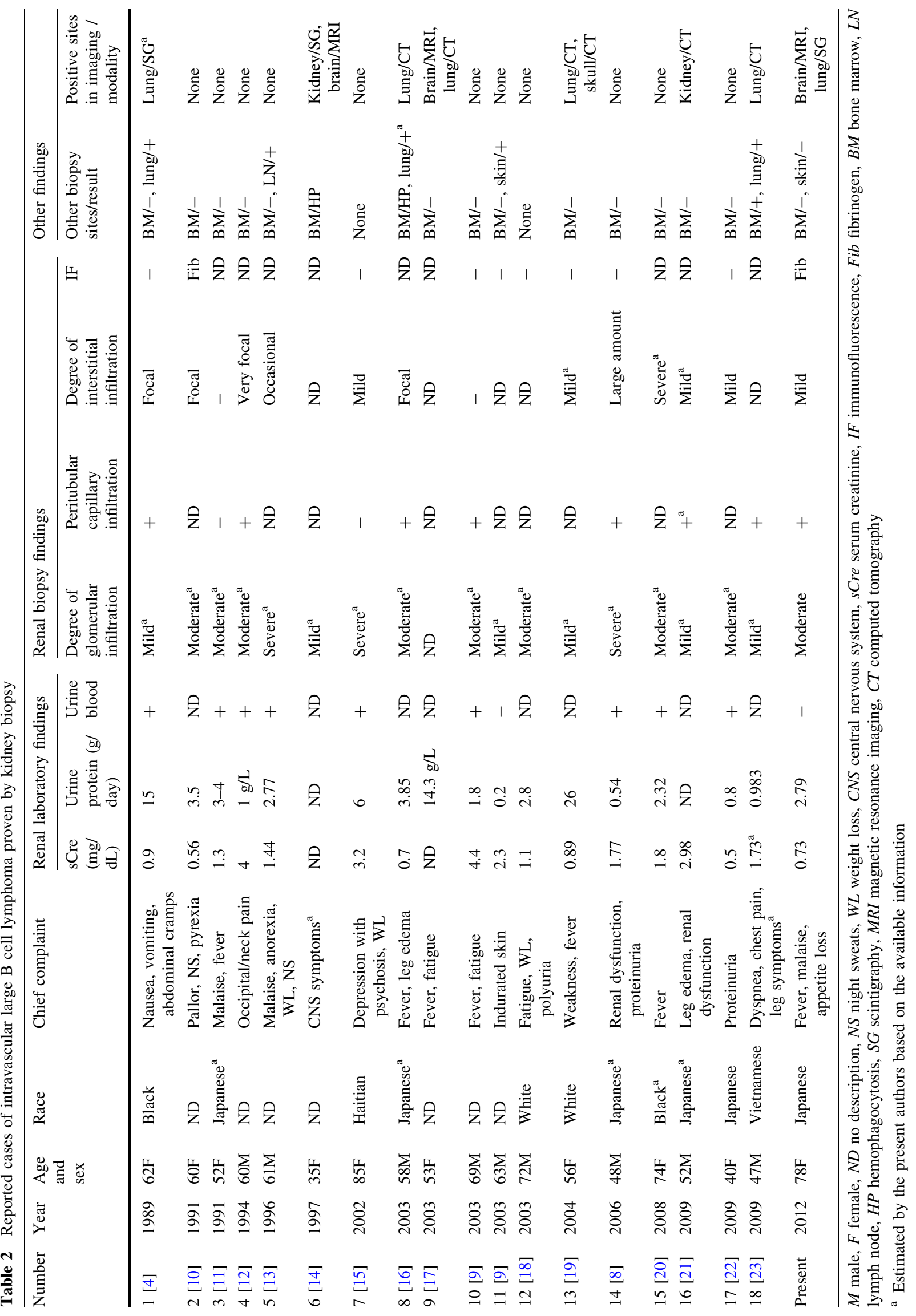


that the kidney was the only biopsy site that revealed endocapillary proliferation of lymphoid cells. In the present case, two bone marrow biopsies, one before and the other after the occurrence of the CNS and pulmonary lesions, and random skin biopsies from three sites were all negative. Murase et al. [2] found bone marrow involvement in $75 \%$ of 96 Japanese IVLBCL cases. However, none of the six Japanese cases in Table 2 showed bone marrow involvement. These contradictory findings suggest that IVLBCL involving the kidney seldom presents with bone marrow infiltration, even in Japanese cases. Urinalysis and kidney biopsy may be warranted in patients with suspected IVLBCL, even if bone marrow biopsy is negative.

In conclusion, this is the case of IVLBCL diagnosed with immunohistochemical staining of a kidney biopsy specimen, an unusual waxing and waning clinical course, and CNS and pulmonary involvement. The differential diagnosis of endocapillary proliferation is important and endocapillary cells should be characterized with immunohistochemical staining, as the clinical course and renal biopsy findings of IVLBCL may mimic other renal conditions.

\section{References}

1. Ferreri AJ, Campo E, Seymour JF, Willemze R, Ilariucci F, Ambrosetti A, et al. Intravascular lymphoma: clinical presentation, natural history, management and prognostic factors in a series of 38 cases, with special emphasis on the 'cutaneous variant'. Br J Haematol. 2004;127:173-83.

2. Murase T, Yamaguchi M, Suzuki R, Okamoto M, Sato Y, Tamaru J, et al. Intravascular large B-cell lymphoma (IVLBCL): a clinicopathologic study of 96 cases with special reference to the immunophenotypic heterogeneity of CD5. Blood. 2007;109: 478-85.

3. Ponzoni M, Ferreri AJ, Campo E, Facchetti F, Mazzucchelli L, Yoshino $\mathrm{T}$, et al. Definition, diagnosis, and management of intravascular large B-cell lymphoma: proposals and perspectives from an international consensus meeting. J Clin Oncol. 2007;25: 3168-73.

4. D’Agati V, Sablay LB, Knowles DM, Walter L. Angiotropic large cell lymphoma (intravascular malignant lymphomatosis) of the kidney: presentation as minimal change disease. Hum Pathol. 1989;20:263-8.

5. Wick MR, Mills SE, Scheithauer BW, Cooper PH, Davitz MA, Parkinson K. Reassessment of malignant "angioendotheliomatosis". Evidence in favor of its reclassification as "intravascular lymphomatosis". Am J Surg Pathol. 1986;10:112-23.

6. Vos JM, Bordbar A, Vet RJ, Pals ST, Kater AP. Waxing and waning intravascular large cell lymphoma with widespread organ infiltration. Leuk Lymphoma. 2011;52:705-8.

7. Meyer GS, Hales CA, Amrein PC, Sharma A, Kradin RL. Case records of the Massachusetts General Hospital. Case 26-2007-a 61-year-old man with recurrent fevers. $\mathrm{N}$ Engl J Med. 2007:357:807-16.

8. Kusaba T, Hatta T, Tanda S, Kameyama H, Tamagaki K, Okigaki $\mathrm{M}$, et al. Histological analysis on adhesive molecules of renal intravascular large B cell lymphoma treated with CHOP chemotherapy and rituximab. Clin Nephrol. 2006;65:222-6.

9. Törnroth T, Heiro M, Marcussen N, Franssila K. Lymphomas diagnosed by percutaneous kidney biopsy. Am J Kidney Dis. 2003;42:960-71.

10. Axelsen RA, Laird PP, Horn M. Intravascular large cell lymphoma: diagnosis on renal biopsy. Pathology. 1991;23:241-3.

11. Nishikawa K, Sekiyama S, Suzuki T, Ito Y, Matsukawa W, Tamai $\mathrm{H}$, et al. A case of angiotropic large cell lymphoma manifesting nephrotic syndrome and treated successfully with combination chemotherapy. Nephron. 1991;58:479-82.

12. Agar JW, Gates PC, Vaughan SL, Machet D. Renal biopsy in angiotropic large cell lymphoma. Am J Kidney Dis. 1994;24:92-6.

13. Wood SM, Boyd SM, Taylor JE, Savill J. A case of non-Hodgkin lymphoma presenting primarily with renal failure. Nephrol Dial Transplant. 1996;11:535-6.

14. Cheng FY, Tsui WM, Yeung WT, Ip LS, Ng CS. Intravascular lymphomatosis: a case presenting with encephalomyelitis and reactive haemophagocytic syndrome diagnosed by renal biopsy. Histopathology. 1997;31:552-4.

15. Shaknovich R, Francois DJ, Cattoretti G, D'Agati VD, Markowitz GS. A rare cause of nephrotic syndrome. Am J Kidney Dis. 2002;39:892-5.

16. Kakumitsu H, Higuchi M, Tanaka K, Shibuya T. Nephrotic syndrome in a patient with intravascular lymphomatosis. Intern Med. 2003;42:98-101.

17. Fozza C, Bonfigli S, Conti M, Dore F, Longinotti M. Longlasting fever of unknown origin preceding the diagnosis of intravascular lymphomatosis: a further case stimulates some remarks. Am J Hematol. 2003;74:211-3.

18. Ozolek J, Nodit L, Bastacky S, Craig F, Nalesnik M. Pathologic quiz case: a 72-year-old man with fatigue and proteinuria. Angiotropic (intravascular) large B-cell lymphoma. Arch Pathol Lab Med. 2003;127:1380-2.

19. Cossu A, Deiana A, Lissia A, Satta A, Cossu M, Dedola MF, et al. Nephrotic syndrome and angiotropic lymphoma report of a case. Tumori. 2004;90:510-3.

20. Yoo J, Kuppachi S, Chander P. Quiz page. Large B-cell lymphoma, intravascular type, with diffuse glomerular and focal interstitial infiltration. Am J Kidney Dis. 2008;51:A43-6.

21. Niitsu N, Okamura D, Takahashi N, Tanae K, Hagiwara Y, Kayano H, et al. Renal intravascular large B-cell lymphoma with early diagnosis by renal biopsy: a case report and review of the literature. Leuk Res. 2009;33:728-30.

22. Kameoka Y, Takahashi N, Komatsuda A, Tagawa H, Hamai K, Hirokawa M, et al. Kidney-limited intravascular large B cell lymphoma: a distinct variant of IVLBCL? Int J Hematol. 2009;89:533-7.

23. Deisch J, Fuda FB, Chen W, Karandikar N, Arbini AA, Zhou XJ, et al. Segmental tandem triplication of the MLL gene in an intravascular large B-cell lymphoma with multisystem involvement: a comprehensive morphologic, immunophenotypic, cytogenetic, and molecular cytogenetic antemortem study. Arch Pathol Lab Med. 2009;133:1477-82.

24. Wang BY, Strauchen JA, Rabinowitz D, Tillem SM, Unger PD. Renal cell carcinoma with intravascular lymphomatosis: a case report of unusual collision tumors with review of the literature. Arch Pathol Lab Med. 2001;125:1239-41.

25. Sawa N, Ubara Y, Katori H, Hoshino J, Suwabe T, Tagami T, et al. Renal intravascular large B-cell lymphoma localized only within peritubular capillaries. Report of a case. Intern Med. 2007;46:657-62.

26. Bai X, Li X, Wan L, Wang G, Jia N, Geng J. Intravascular large B-cell lymphoma of the kidney: a case report. Diagn Pathol. 2011;6:86. 